\title{
ARTURO, SANDRA, POLI Y CECILIA: CUATRO CASOS PARADIGMÁTICOS DE LA JURISPRUDENCIA ARGENTINA.
}

GUSTAVO FEDERICO de BAGGIS1

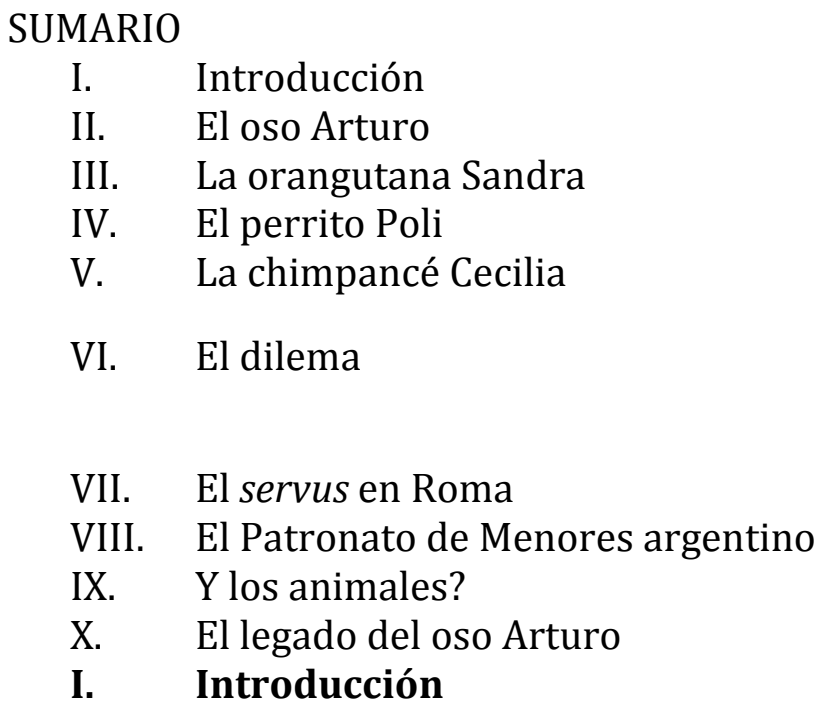

El presente ensayo pretende evidenciar en cuatro casos paradigmáticos, cómo el derecho jurisprudencial argentino, a través de los fallos de distintos tribunales de diversa jerarquía, han marcado una línea divisoria a partir de la cual el sostener a los animales dentro de la categoría jurídica de "cosas" resulta, por lo menos, contradictorio y falaz.

El oso Arturo, la orangutana Sandra, el perrito Poli y la chimpancé Cecilia son ya un hito a partir del cual el pensamiento jurídico sobre la naturaleza jurídica de

\footnotetext{
1 Abogado de la Universidad Nacional del Litoral, Argentina; Mediador del Colegio de Abogados de Mendoza, Argentina; Doctor ("cum laude") por la Universidad Autónoma de Barcelona; Magister en Sistema jurídico romanístico, unificación del derecho y derecho de la integración, Universidad de Roma Tor Vergata; Diploma en estudios profundizados en Derecho Internacional Público y Relaciones Internacionales, Universidad Autónoma de Barcelona; Curso de Perfeccionamiento en Derecho de la integración y unificación del derecho en el sistema jurídico romanistico (derechos europeos y derecho latinoamericano), Ministerio de Relaciones Exteriores - Consejo Nacional de Investigaciones $(C N R)$ - Universidad de Roma Tor Vergata; ex profesor de Derecho Romano de la Universidad Autónoma de Barcelona; profesor de Derecho Romano de la Universidad Nacional de Cuyo, Argentina; funcionario del Poder Judicial de la Provincia de Mendoza, Argentina; miembro de la Asociación Latinoamericana de Derecho Animal (ALDA), miembro del International Center for Animal Law and Policy - ICALP, de la Universidad Autónoma de Barcelona, dirigido por la Profesora Teresa Giménez-Candela.-
} 
los animales comienza a transitar un camino más claro, más justo y equitativo. Son ellos los personajes involuntarios de una película cuya trama no es feliz -porque sufrieron, o sufren aún, las consecuencias de haber sido privados de su libertad, el maltrato, el desarraigo de su hábitat natural y la modificación de sus hábitos naturales, entre otras vicisitudes-, pero que deja al espectador un mensaje profundo y esclarecedor: el cambio de paradigma del animal como objeto del derecho al de sujeto de la tutela del sistema jurídico.

En los casos que nos ocupan, han sido los jueces quienes han tomado la delantera por sobre la doctrina jurídica y han dado el paso adelante que durante años, siglos, los pensadores del derecho sólo habían podido teorizar.

Los jueces y también las organizaciones animalistas que promovieron distintas medidas protectorias de los animales, que obligaron al órgano jurisdiccional a tomar una posición que, en alguno de estos casos, ha sido señera en el ámbito del derecho y de la sociedad civil en su conjunto.

\section{El oso Arturo}

Todo comenzó en Mendoza, la ciudad más importante del oeste argentino, construida al pie de la cordillera de los Andes, en un clima desértico que promedia los $8^{\circ}$ en invierno y los 38ํㅜ en verano. En su zoológico vivía Arturo, un oso polar.

Un oso polar puede vivir hasta 20 años en su hábitat natural y en un contexto de encierro puede llegar a vivir hasta 26 años aproximadamente. Arturo llegó al zoológico de Mendoza cuando tenía ocho años, en 1993.

En el verano del 2014 se produjo un hecho que fue observado y filmado por activistas de una organización protectora de animales, en un día de intenso y sostenido calor: el oso Arturo, sofocado, recorría desesperadamente su estanque con el equipo de refrigeración fuera de servicio.

Las repercusiones que tuvo este caso en Argentina y países limítrofes fueron muy importantes, y las organizaciones ambientalistas y de protección a los animales, -Greenpeace, entre otras- exigieron el traslado inmediato del oso a una reserva de osos polares en Canadá. 


\section{dA derecho ANIMAL la web center de los animales con derecho}

Otra organización animalista, en cambio, presentó un habeas corpus en la Justicia provincial en favor de Arturo, el cual fue rechazado ad líminem por improcedente.

La decisión valiente y razonable que tomó el director del zoológico, -luego de convocar a una junta de veterinarios de los mayores zoológicos de la Argentina, Uruguay, Chile y de la reserva canadiense, para asesorar sobre la salud y hábitat del oso, como su posible traslado a una reserva de osos en el polo norte- fue mantener al oso en Mendoza. La vida de Arturo corría mayor peligro frente a un traslado de esa naturaleza que manteniendo su statu quo.

Finalmente, el 3 de julio de 2016, Arturo falleció, producto de un marcado deterioro de su salud por lo avanzado de su edad, que derivó en pérdida de apetito y la disminución de su peso corporal, visión y olfato. Arturo llevaba 22 veranos viviendo en Mendoza y era la quinta generación de su familia nacida en cautiverio.

\section{La orangutana Sandra}

"Orangutana Sandra s/ recurso de casación s/habeas corpus"

(Tribunal: Cámara Federal de Casación Penal, Ciudad Autónoma de Buenos Aires, Argentina)

Un verano después, en el mes de noviembre del 2014, en la Ciudad de Buenos Aires, otra asociación proteccionista, en este caso AFADA - Asociación de Funcionarios y Abogados por el Derecho de los Animales, -representada por el abogado Pablo Buompadre, y patrocinada por el constitucionalista Andrés Gil Domínguez-, presenta un recurso de habeas corpus ante un Juzgado de Instrucción de la ciudad de Buenos Aires, en favor de la orangutana Sandra, del zoológico de dicha ciudad, a fin de requerir su urgente liberación y su posterior e inmediato traslado y reubicación en un santuario de primates de Sorocaba, Brasil. 


\section{dA derecho ANIMAL la web center de los animales con derecho}

El pedido fue rechazado por el juzgado, la medida fue luego apelada ante la instancia superior (Cámara del Crímen) y también rechazada.

En dicha apelación, la asociación proteccionista alegó que Sandra, un animal con probada capacidad cognitiva, se encontraba "privada ilegítima y arbitrariamente de su libertad, en un confinamiento injustificado" y pedía "que pudiera vivir entre sus congéneres en un lugar adecuado", solicitando su liberación y traslado a un santuario de primates.

Finalmente, la instancia de casación penal, revirtió esa sentencia al hacer lugar al argumento que consideraba que se trataba de un "confinamiento injustificado de un animal con probada capacidad cognitiva". AFADA había argumentado que la orangutana estaba sufriendo por el encierro y por estar exhibida ante las personas que visitan el zoológico.

El fallo de casación, lamentablemente, careció de una fundamentación jurídica exhaustiva. Sólo hizo mención a dos trabajos doctrinales del jurista Eugenio Raúl Zaffaroni², para justificar la aplicación de una "interpretación jurídica dinámica y no estática" por la cual reconoce al animal el carácter de sujeto de derechos.

Pero más allá de la ausencia de una deseable reseña argumentativa, el fallo que nos ocupa fue sin dudas señero, tal como sostuvo el prestigioso constitucionalista Daniel Sabsay al sostener que «más allá de la vaguedad argumentativa en la que se funda el fallo, al citar obras que no son específicas de estas cuestiones, tiene un gran valor, puesto que reconoce la calidad de personas no humanas a este tipo de animales con altas capacidades cognitivas y afectivas» ${ }^{3}$.

\footnotetext{
2 Vid Zaffaroni, Eugenio Raúl, Derecho Penal - Parte General, Ediar, Buenos Aires, 2002, y también, Idem, La Pachamama y el humano, Ediciones Colihue, Buenos Aires, 2011.

${ }^{3}$ Citado en http://www.lanacion.com.ar/1754353-conceden-un-habeas-corpus-a-una-orangutana-del-zoologicoporteno.
} 
El fallo Sandra es histórico porque sentó un precedente radical en la jurisprudencia argentina, -que hasta ese momento consideraba a los animales como cosas-, al quitarle a la orangutana la calidad de "objeto" para tener derechos similares a los de los humanos.

En la práctica puso fin al tratamiento de los animales como una cosa mueble4, para ubicarlos en la categoría de "persona no humana", aplicando de manera dinámica la previsión de los artículos 51 y 52 del Código Civil argentino, según el cual "todos los entes que presentasen signos característicos de humanidad, sin distinción de cualidades o accidentes, son personas de existencia visible" y, como tales, "capaces de adquirir derechos o contraer obligaciones" ${ }^{5}$. Contexto en el cual el pronunciamiento judicial reconoció a Sandra, y por carácter transitivo a los grandes simios, tres derechos elementales: a la vida, a la libertad física y a no ser maltratados de ningún modo. Derechos básicos frente a los cuales debía ceder la propiedad privada.

\section{El perrito Poli}

"F. c/ Sieli Ricci, Mauricio Rafael p/ maltrato y crueldad animal" (Tribunal: Primer Juzgado Correccional. San Martin, Mendoza, Argentina)

El tercer caso se produce en el mes de enero de 2015 en Palmira, una pequeña ciudad de la Provincia de Mendoza, Argentina, cuando un vecino de la misma, alterado por los ladridos de un perro callejero que no le permitía dormir la siesta, decidió amarrarlo con una soga a la parte trasera de su vehículo y arrastrarlo a toda velocidad por las calles de la ciudad.

\footnotetext{
${ }^{4}$ Código Civil argentino, art. 2311 y ss.
}

${ }^{5}$ Código Civil argentino, art. 52. 
La providencial presencia e intervención de dos personas que esperaban en la parada del bus, y vieron pasar un vehículo que llevaba un perro atado con un collar y correa a su paragolpes trasero, e iba arrastrándose por el pavimento. Siguieron corriendo a la camioneta para tratar que el sujeto detuviera su marcha y observaron que más adelante que el conductor se detuvo, le quitó la correa al perro y lo dejó tirado, herido, al costado de la ruta, lo que afirma la indolencia del conductor de la camioneta por el sufrimiento del animal.

Fue entonces que se acercaron al animal y vieron que tenía todas las patitas y la panza llenas de sangre y que no se podía levantar, y dieron aviso inmediato a la Policía. Al llegar los funcionarios policiales trasladaron de inmediato al can a una veterinaria $\mathrm{y}$, posteriormente individualizaron $\mathrm{y}$ detuvieron al propietario del vehículo.

El perrito, a partir de ese momento llamado "Poli", -en honor a la denodada labor de los policías que no dudaron en socorrerlo y llevarlo con urgencia a la veterinaria-, sobrevivió milagrosamente, luego de varios días de cuidado permanente dada la gravedad de sus heridas.

La también histórica sentencia de este caso, tiene una particularidad: fue promovida de oficio por el agente fiscal, a la que luego adhirió la asociación proteccionista A.M.PA.R.A. (Asociación Mendocina de Protección, Ayuda y Refugio del Animal) en calidad de querellante particular; y fallada por el procedimiento de juicio abreviado por el juez de primera instancia Darío Dal Dosso, juez competente de la Justicia Correccional (interviene en delitos menores, con penas leves), quien llevó adelante el juicio con una profesionalidad y sensibilidad inusitadas.

El Dr. Dal Dosso fundamentó su resolución luego de un estudio pormenorizado y certero del bien jurídico protegido y dictó, por primera vez en la historia jurisprudencial argentina, una sentencia que califica legalmente al perro Poli la condición de "persona no humana", más allá de adherir a los fundamentos 
de la sentencia previamente citada de la orangutana Sandra que en virtud de una interpretación dinámica y no estática, reconoce al animal la calidad de "sujeto de derecho". Y esta primicia es tal porque el fallo del juez no tuvo repercusión en los medios periodísticos o académicos, más allá de que el caso sí fue conocido por lo aberrante del hecho. El juez habló por su fallo, a la vieja usanza, y evitó cualquier tipo de injerencia de los medios de comunicación masivos.

Por cierto, el conductor del vehículo fue imputado por las figuras de maltrato y crueldad animal, a una pena de prisión en suspenso y la obligación de proveer a un refugio canino alimento para perros por un tiempo determinado.

\section{La chimpancé Cecilia}

"Presentación efectuada por A.F.A.D.A. respecto del chimpancé "Cecilia" - sujeto no humano"

(Tribunal: Tercer Juzgado de Garantías. Mendoza, Argentina)

En el año 2016, nuevamente la Asociación de Funcionarios y Abogados por el Derecho de los Animales - AFADA, promueve un recurso de hábeas corpus en favor de la chimpancé Cecilia del Zoológico de Mendoza, atento a que la misma "ha sido privada ilegítima y arbitrariamente de su derecho de la libertad ambulatoria y a una vida digna" por parte de las autoridades del zoológico; porque su estado de salud físico y psíquico se halla profundamente deteriorado y empeorando día a día con riesgo de muerte. La asociación protectora peticiona la liberación de la chimpancé y su posterior traslado al santuario de Sorocaba, Brasil.

Cecilia, para ese entonces tenía 30 años y estaba sola desde el año 2014 cuando sus compañeros de jaula murieron por causas naturales.

En el mes de noviembre de 2016, la jueza Alejandra Mauricio, también de un juzgado de primera instancia, dicta una sentencia que tomó una amplia difusión nacional y mundial, por considerar a Cecilia como "sujeto de derechos no 


\section{dA derecho ANIMAL la web center de los animales con derecho}

humano", y dispuso su traslado al santuario de Sorocaba. Aunque, insistimos, ya en el caso Poli se había declarado como tal más de un año antes.

Agregó, además, que dicha medida "no intenta igualar a los seres sintientes con los seres humanos como así tampoco se intenta elevar a la categoría de personas a todos los animales o flora y fauna existente, sino reconocer y afirmar que los primates son personas en tanto sujetos de derechos no humanos".

En el mes de marzo de 2017 Cecilia fue trasladada con éxito al santuario, y lleva adelante su período de adaptación para poder tomar contacto con otros congéneres.

\section{El dilema}

Los casos que hemos analizado precedentemente, aunque de manera breve, nos hacen pensar en el cambio de paradigma que proponemos y que han sido materializados en los tres últimos, que han tenido resoluciones favorables de distintos tribunales de justicia.

Pero no es el caso del oso Arturo, que no tuvo recepción dentro del órgano jurisdiccional, que oportunamente rechazó ad líminen un hábeas corpus interpuesto a su favor.

No obstante ello, el caso Arturo ha tenido una gran repercusión y generó grandes debates, hasta el mismo día de su muerte.

Arturo enfrentó a la sociedad con sus propias contradicciones.

Enfrentó al hombre a un dilema ético cuyas respuestas no distan de las enunciadas mucho antes por Descartes, que consideraba que los animales no tenían alma, por lo que no podían sentir y, por eso, no merecían ninguna consideración; o John Locke, que argumentaba que la crueldad con los animales tendría efectos negativos sobre la evolución ética de los niños, que más tarde transmitirían esa brutalidad hacia los seres humanos...

Aún hoy observamos que la impronta cartesiana rige inalterable en el ámbito jurídico; por ello muchos juristas afirman que los animales no pueden ser sujetos de derecho, al no poder contraer obligaciones. 
Sin embargo, en el planeta el derecho está evolucionando como ciencia y filosofía. En la Amazonía boliviana, por ejemplo, donde los nómadas tratan de alimentarse más de frutos que de animales, cuando sacrifican a uno de ellos le piden perdón y le explican su necesidad. En el Altiplano los animales son queridos y tratados como parte de la familia, porque creen en el "ajayu", que en lengua aymará significa el alma, el espíritu, la energía que posee todo lo que nos rodea ${ }^{6}$.

Tomo el ejemplo de Bolivia por el debate que se dio allí al dictarse su nueva constitución frente a la posibilidad de proteger a la "Pachamama", que, como sabemos, no sólo representa la tierra como tal, sino también la capa de ozono, los bosques, los ríos, los lagos, las montañas y, por supuesto, los animales. Todo lo que rodea al ser humano es la "Pachamama", que tampoco puede contraer contratos ni obligaciones, pero que en esa cultura es el pilar del respeto por toda forma de vida y que finalmente incorporó a su nueva Constitución "los derechos de la naturaleza", equiparándolos con los derechos humanos.

La sociedad humana acepta, mayoritariamente, que el sufrimiento y la muerte son cosas negativas, y que ayudar a los demás es algo positivo. Nada justifica el obtener un beneficio a costa de causar daños a los demás. Ya los romanos reflejaban este principio en la máxima "alterum non laedere", no dañar a otro, que rige aún en los ordenamientos jurídicos occidentales.

Ahora, por qué no sucede lo mismo en el caso de los humanos con los animales no humanos?

Las respuestas son tan variadas como las ramas del saber que estudian este fenómeno, pero -de una u otra manera-, justifican o repudian la conducta especista del ser humano para con los animales no humanos.

\footnotetext{
${ }^{6}$ PEÑA AGUILAR, Amelia, "Por los derechos de los animales", en La Razón (Edición Impresa), La Paz - Bolivia, 14/1/2014, encontrado en: http://www.larazon.com/suplementos/la_gaceta_juridica/derechosanimales_0_1979202139.html
} 
En cambio, la respuesta dada hasta aquí en el plano jurídico es más simple. La mayoría de los ordenamientos jurídicos distingue, por un lado, las cosas y por otro, las personas; y sólo reconoce derechos a las personas por ser poseedoras de su rasgo más característico: la voluntad.

Pero las personas, es importante tener esto en cuenta, no son sólo los seres humanos. Una empresa, un organismo público, una fundación, una universidad, son ejemplos de persona. Personas que, a través de sus representantes en estos casos, o de sí mismas en el caso de las personas humanas, ejercen sus derechos, velan por ellos y accionan judicialmente ante cualquier atropello en su contra. Acciones que no sería posible ejercer sin la presencia de voluntad en estos sujetos, esto es, que las realicen con intención, discernimiento y libertad.

Entonces, el silogismo sería el siguiente: si soy humano, tengo voluntad, si tengo voluntad, tengo derechos; ergo, si no tengo voluntad, no tengo derechos. Por tanto, si no soy humano, no tengo derechos. Esta fórmula dialéctica funciona de tal manera que no da lugar a una categorización inclusiva a los animales.

Por ello resultan ilusorias las reivindicaciones de derechos para los animales. Al reivindicar que éstos sean reconocidos como personas legales con derechos, ello implica que sus intereses serán protegidos jurídicamente; reivindicación que no encaja en el silogismo anterior.

No obstante, existen y han existido en siglos pasados, figuras que tampoco encajan en ese silogismo: la esclavitud y la segregación racista, el derecho al sufragio exclusivamente masculino, el sexismo, la pertenencia a una determinada religión o culto, entre otros, que ya no resultan aceptables al día de hoy, al menos para la mayoría de la gente.

Por ello, analizaremos dos figuras que -salvando distancias de tiempo y lugar, demuestran un cambio de paradigma que traduce una evolución cultural del ser humano: el servus en Roma y, más modernamente, el Patronato de Menores de la Argentina. 


\section{El servus en Roma}

La esclavitud es un fenómeno social, común a todos los pueblos de la antigüedad, y Roma no fue una excepción. Pero es cierto que alcanzó su apogeo en la gran expansión territorial de la etapa imperial, para la cual fue un elemento imprescindible ${ }^{7}$.

Fue ya en época post-clásica que por la crisis económica que atravesaba Roma disminuyó paulatinamente la mano de obra servil, que ya no se renueva en las campañas bélicas; sumado al influjo de la legislación cristiana que, si bien no pretendió abolir la esclavitud, contribuyó decididamente a mejorar las condiciones de vida de los esclavos y a favorecer progresivamente su liberación, partiendo del principio de la libertad natural de los hombres.

No obstante estos cambios sociales, la realidad de los esclavos no sufrió alteraciones. Desde el punto de vista jurídico, fueron siempre considerados como cosas de propiedad de su dueño (res mancipi) y, como tales, sometidas al derecho de vida y muerte que el dominus ejercía sobre ellas.

Hasta aquí, el esclavo encuadra perfectamente en el silogismo. Es una cosa, ergo, no es una persona y, como tal, no tiene derechos. Salvo por un detalle: su naturaleza jurídica no sólo era de cosa; para el ordenamiento jurídico romano los esclavos tenían una doble posición: son cosas de propiedad de su dueño y a la vez seres humanos.

Esta aparente paradoja, se revela en algunos ejemplos como los siguientes: el respeto al sitio de su sepultura; la condena al dominus que lastimara o ejerciera abusivamente su poder sobre su esclavo; la prohibición para que el dominus vendiera esclavos para los espectáculos con fieras en el circo; la concesión de libertad al esclavo enfermo abandonado por su dueño; la condena por la muerte de un esclavo propio igual que la de un esclavo ajeno; la represión de la crueldad intolerable del dueño; o la posibilidad de que el esclavo tuviera una pequeña cantidad de bienes (peculium) para su administración personal.

\footnotetext{
${ }^{7}$ Vid GIMÉNEZ-CANDELA, Teresa, “Derecho romano privado", Tirant lo Blanch, Valencia, 1999.
} 


\section{dA derecho ANIMAL la web center de los animales con derecho}

Ejemplos, entre otros, que demuestran rasgos de humanidad del ordenamiento jurídico romano para con los esclavos -inspirados por la filosofía estoica y luego por el cristianismo-, traducidos en distintas normas que atemperan la dominica potestas de los dueños.

\section{El Patronato de Menores argentino}

Entre los años 1919 y 2005 tuvo vigencia en Argentina la ley de Patronato de Menores.

Durante todo ese tiempo, el Patronato del Estado era la función que este cumplía con el fin de asistir, educar, ejercer la guarda y la representación de los menores de edad que no tenían representantes, o que no obstante tenerlos se encontraban en situación de abandono o peligro.

El Estado intervenía subsidiariamente ante la falta de representantes legales o cuando estos no cumplían con el cometido fundamental de la patria potestad y los menores se encontraban en peligro material o moral, a fin de ejercer la protección activa del menor y su formación.

El menor, tal como se denominaba al niño en ese paradigma, quedaba directamente a cargo del Estado cuando los padres hubieran perdido la patria potestad o cuando hubieran sido suspendidos en su ejercicio, y cuando los menores de 18 años hubieran comparecido ante el juez como acusados o víctimas de un delito, siempre que se encontraran material o moralmente abandonados o en peligro moral.

En síntesis, el niño era "cosificado" como un objeto de control. Se desnaturalizaba la capacidad jurídica que le otorgaba la legislación común argentina, y el menor dejaba de ser, en la praxis, un sujeto pleno de derechos para pasar a ser un mero objeto de imputación normativa. Se convertía en un incapaz que no tenía posibilidad alguna de decidir sobre su vida, y en él recaía el control más absoluto de un Estado que -en el mejor de los escenarios- lo internaba en un instituto de menores desentendiéndose de su vida, salvo por esporádicos actos procesales en 
el que le imponían tratamientos, controles, oficios o una educación sobre los cuales el niño no tenía ninguna posibilidad de decidir. El sistema estaba hecho para que el niño obedeciera, no para que opinara, ni mucho menos optara, eligiera...

$\mathrm{Al}$ introducirse en el derecho nacional la Convención sobre los Derechos del Niño se produce un cambio de paradigma: el niño deja de ser un objeto de derecho para asumirse como un sujeto pleno de derechos, como una persona total, un ser humano completo y respetado; poseedor de un conjunto de recursos y potencialidades, titular de derechos civiles, políticos, sociales, culturales y económicos. E introduce también, y esto es realmente trascendente, palabras inusuales en el vocablo jurídico: el preámbulo de la convención pronuncia las palabras "comprensión”, "amor" y "felicidad" como elementos imprescindibles para el crecimiento del niño.

\section{Y los animales?}

Hemos visto que los animales son definidos como cosas, y también cómo en distintos momentos y contextos de la historia, existieron seres humanos reducidos a cosas, en los derechos o en los hechos. El vínculo común entre estos últimos es que fueron objeto de un cambio de paradigma: ambos se transformaron en sujetos de derechos. En cambio, los animales aún esperan el cambio de paradigma que les otorgue una protección humana adecuada.

Tal vez a estas situaciones podríamos asociar el argumento de John Locke cuando pensaba que la crueldad con los animales tendría efectos negativos sobre la evolución ética de los niños.

Los humanistas antropocentristas quieren restringir la idea de persona a la clase "seres humanos", y negársela a los animales; amparados en su falta de voluntad. Pero no resuelven la contradicción lógica que presentan los seres humanos en estado embrionario o en estado terminal, los deficientes mentales, los incapaces, etc., que incumplen en igual medida que los animales el concepto ideal y perfecto de "persona". Si a estos seres humanos se les sigue considerando "personas", por qué se les niega esa acepción a los animales no humanos? 
Es cierto que es difícil pensar en un animal como persona no humana. Pero también es difícil pensar en un ser humano sin animales y sin un medio ambiente sano.

Entonces sería necesario un cambio de paradigma en los fundamentos éticos: si buscamos no sólo el bien del ser humano, sino también el de las cosas no humanas, incorporaríamos al concepto de bien el cuidado de los animales y del medio ambiente . $^{2}$

Ahora bien, aunque se pueda atribuir tanto a los animales como a las realidades inanimadas un cierto valor y dignidad, lo son de modo relativo y no igual al valor y dignidad humana. En ese sentido, podemos aceptar que los animales tienen "derechos" y los seres humanos "deberes" hacia ellos.

El derecho natural -en el caso de la esclavitud-, los derechos humanos -en el caso de los niños del patronato-, o los derechos de los animales, tienen inexorablemente una base ética que halla su fundamentación en lo que Alejandro Herrera denomina "la regla de oro de la ética": "no hagamos a otros lo que no queramos que nos hagan a nosotros". Por tanto, nosotros no queremos que nadie nos haga mal y nos encantaría que todos nos hicieran el bien.

De tal modo, se podría reformular la regla diciendo que debemos hacer el bien y evitar el mal. 0 dicho de otro modo, procurar el bienestar de alguien y no provocarle malestar. Y como el bienestar de alguien consiste en que mantenga a salvo su integridad física y mental, en que pueda desarrollarse adecuadamente de acuerdo a su naturaleza y, en última instancia, en que pueda mantenerse con vida, podemos especificar el imperativo de hacer el bien o procurar el bienestar en términos de proteger la integridad, el desarrollo y la existencia de los animales no humanos.

\footnotetext{
${ }^{8}$ Vid JONAS, Hans, El principio de responsabilidad: Ensayo de una ética para la civilización tecnológica, Barcelona, Herder, 1995, 35.
} 


\section{dA derecho ANIMAL la web center de los animales con derecho}

Entonces, si reconocemos la obligación moral de extender a los animales no humanos la aplicación de la regla de oro de la ética, fácilmente podemos deducir que los animales tienen derecho a que nosotros respetemos esa regla.

Pero cierto es también que dichos deberes no pertenecerían al mismo nivel o condición que los deberes que rigen entre los seres humanos ${ }^{9}$. Técnicamente, ubicaríamos a los animales como legitimados pasivos, receptores de nuestra obligación de respetar los derechos de los que son poseedores. Y en la medida que esos derechos son relativos y limitados por los derechos de los seres humanos, debiéramos cambiar nuestras actitudes hacia los animales por una de respeto, estima, conocimiento, comprensión, protección y cuidado, en palabras de Sánchez González ${ }^{10}$, y generar normas de conducta humanas que eviten el sufrimiento y la crueldad animal, la regulación del uso de animales en laboratorios, en espectáculos, en el uso ganadero, etc.

A tal fin, sería interesante pensar en la figura de un ombudsman de los animales, que actúe no sólo como defensor de las acciones colectivas tendientes a proteger a los animales de la crueldad humana, sino como un garante de la legitimación pasiva que poseen los animales respecto a derechos que deben ser respetados por los humanos.

\section{El legado del oso Arturo}

Arturo, como relatamos en el principio, falleció por causas naturales sin conocer su ámbito natural, sin conocer la libertad.

Pero su caso dejó instalada en la sociedad, tal vez por primera vez, la idea firme y sostenida de que los animales deben tener derechos, que deben ser

\footnotetext{
${ }^{9}$ BERLOEGUI, Carlos, Ética animal e idea de persona, 12.

10 SÁNCHEZ GONZÁLEZ, Miguel A., "El debate ético actual sobre la relación del hombre con los animales", en LACADENA, J. R. (ed.), Los derechos de los animales, Madrid, UPCO/Bilbao, Desclée de Brouwer, 2002, 130-131.
} 
respetados por los seres humanos, y que los seres humanos debemos proveer a que esos derechos sean cumplidos.

Arturo, al menos en la sociedad mendocina, dejó instalada la idea y el debate de promover el cierre del parque zoológico, que finalmente se cumplió a principios de este año. Aunque con un final incierto para cientos de especies que aún lo habitan.

Salvo Cecilia, que fuera trasladada a un santuario por orden judicial, el resto de los animales siguen viviendo en el zoológico que cerró sus puertas, pero sigue funcionando detrás de ellas.

Y el problema actual, que aún no se debate con la seriedad que corresponde, es ¿qué hacer con los animales que aún viven?, pues la mayoría de ellos -por distintos motivos- no podrían vivir en libertad, o no existen los medios económicos o una infraestructura para trasladarlos a sitios donde puedan vivir con la dignidad que ahora no tienen. $\mathrm{O}$ peor aún, no existe ni la vocación ni la decisión política de encontrar una solución.

Aunque sabemos que la solución ideal ya no existe, pues consistiría volver al estado natural a animales que no podrían defenderse, alimentarse, sostener su salud en ámbitos geográficos en los que jamás han estado o de los que fueron retirados de muy pequeños; pareciera que la solución para los animales que aún habitan en el Zoológico de Mendoza, o en cualquier zoológico, es que mueran allí. Y tal vez esa sea una solución, en la medida que no puedan regresar a sus ámbitos naturales, pero aún así estamos obligados a proveerles a un ámbito lo más digno posible donde pasar sus últimos días.

Las soluciones que han brindado la justicia en los distintos casos que hemos enumerado, tienen, por supuesto, un alcance individual sobre los animales objeto del litigio. No sirven ni alcanzan para resolver la situación de todos los demás, pero per se ya implican un cambio de paradigma.

Y no olvidemos que el cambio de paradigma jurídico más importante del siglo pasado se estableció en un instrumento con escaso valor positivo en su momento y con una fórmula aparentemente simple y elemental: "todo ser humano es persona". De ese modo, la comunidad internacional archivó el paradigma racista en el artículo 
primero de la Declaración Universal de Derechos Humanos de 1948, pero lo expresó sólo en forma de declaración, lo que no tiene mucho valor preceptivo en el derecho internacional público, alcanzado sólo décadas después, al considerarla parte de la Carta de la ONU y al ratificarse los Pactos Internacionales de Derechos Civiles y Políticos y Económicos, Sociales y culturales.

Por eso, es auspicioso que los nuevos conocimientos y valores de la sociedad humana arriben a un estadio de la evolución en el que se considere el derecho de los animales, del medio ambiente, de los recursos naturales a ser protegidos enfáticamente por la jurisprudencia y por la normativa legal del mismo modo en que lo son los derechos fundamentales del hombre.

Para finalizar, hacemos propia la expresión del eminente jurista argentino Eugenio Zaffaroni: "a nuestro juicio, el bien jurídico en el delito de maltrato de animales no es otro que el derecho del propio animal a no ser objeto de la crueldad humana, para la cual es menester reconocerle el carácter de sujeto de derechos"11.

${ }^{11}$ ZAFFARONI, Eugenio R., "La Pachamama y el humano", Ed. Colihue, Buenos Aires, 2012, 